Fig. 1C

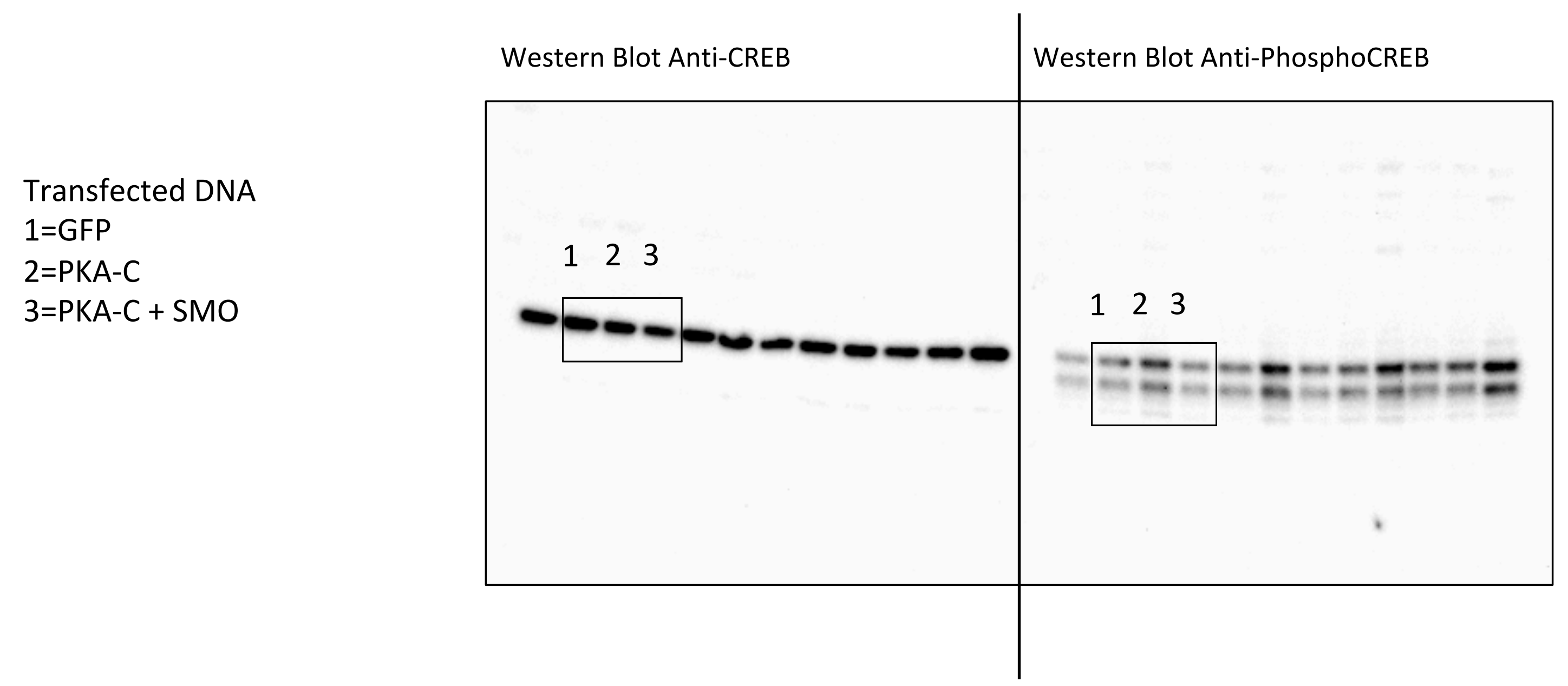


Fig. S1D

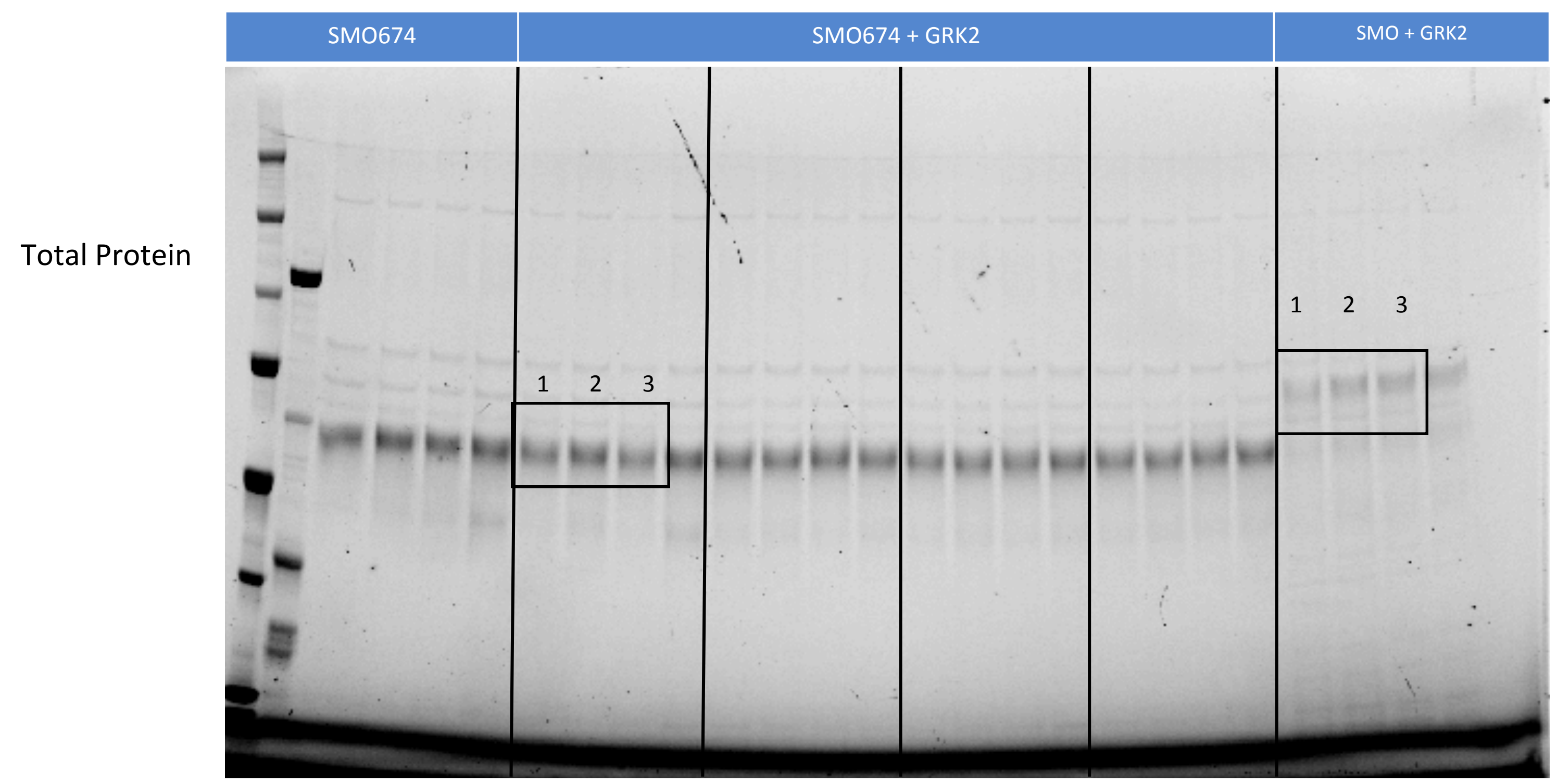

$1=$ vehicle; $2=\mathrm{KAAD} ; 3=\mathrm{SAG} 21 \mathrm{~K}$ 
Fig. 3C

LiCor (WB) in IMCD3

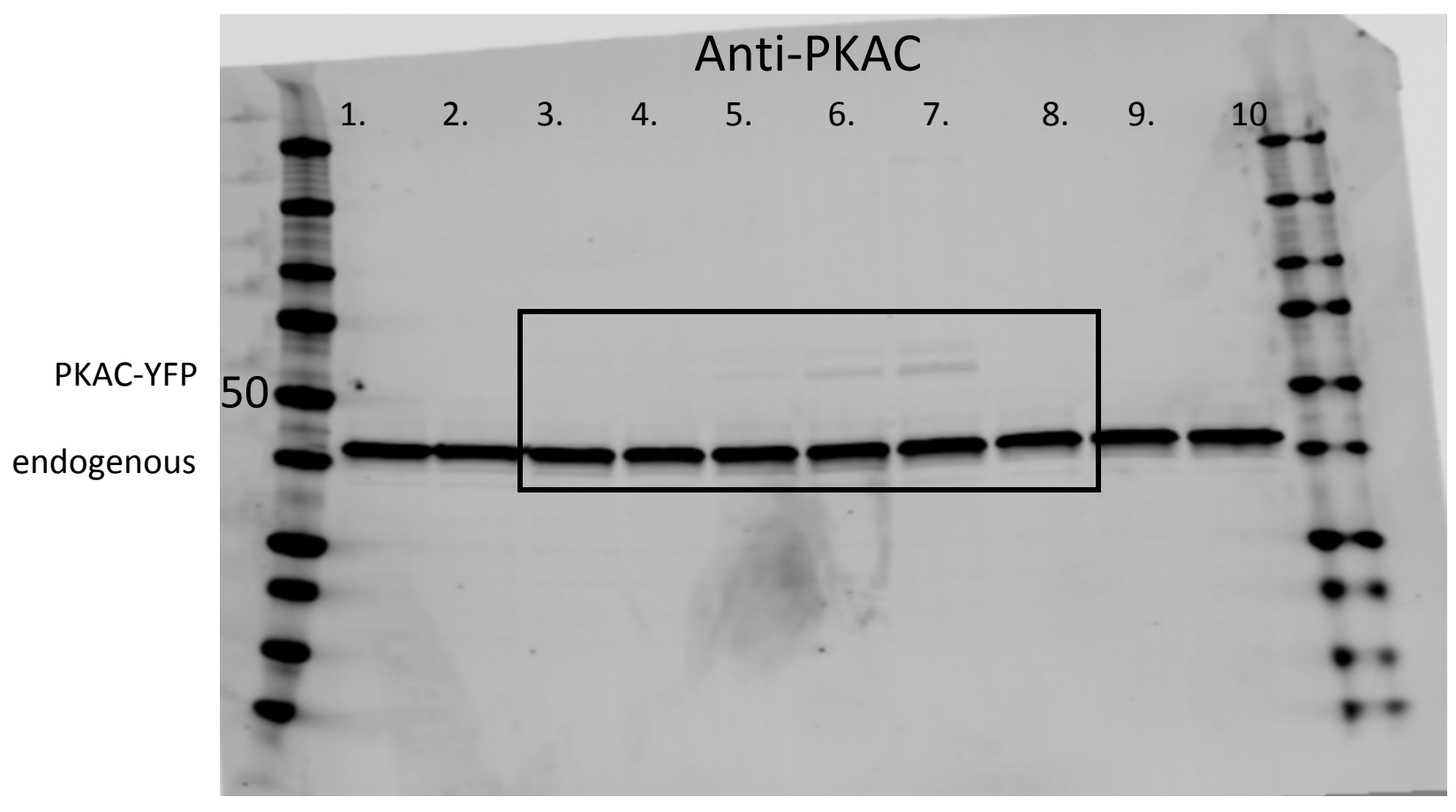


Anti-FLAG M1 and anti-GFP

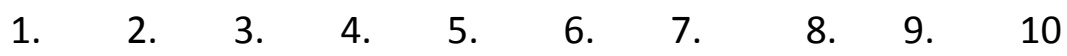

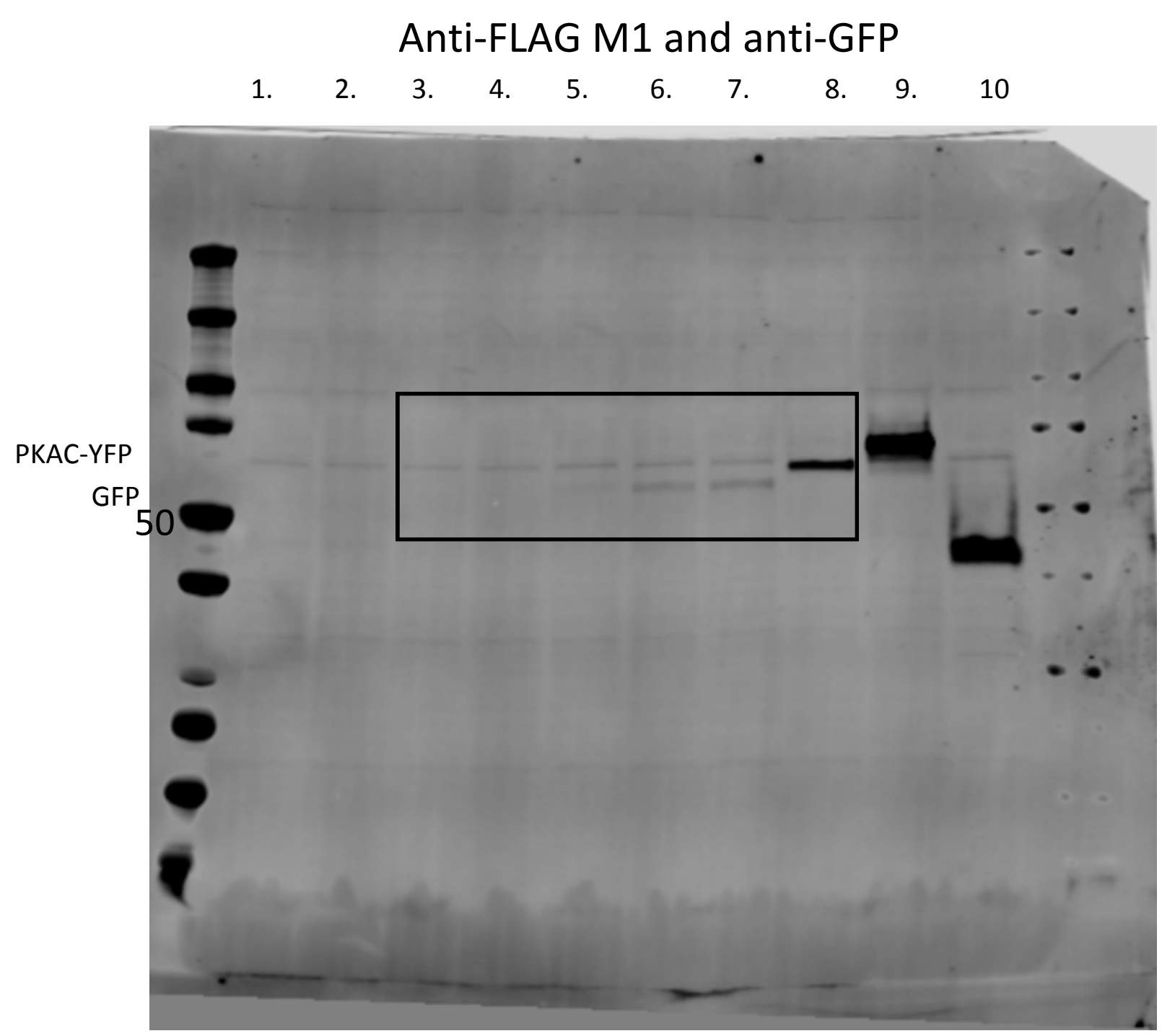 \\ Fig. 3C}



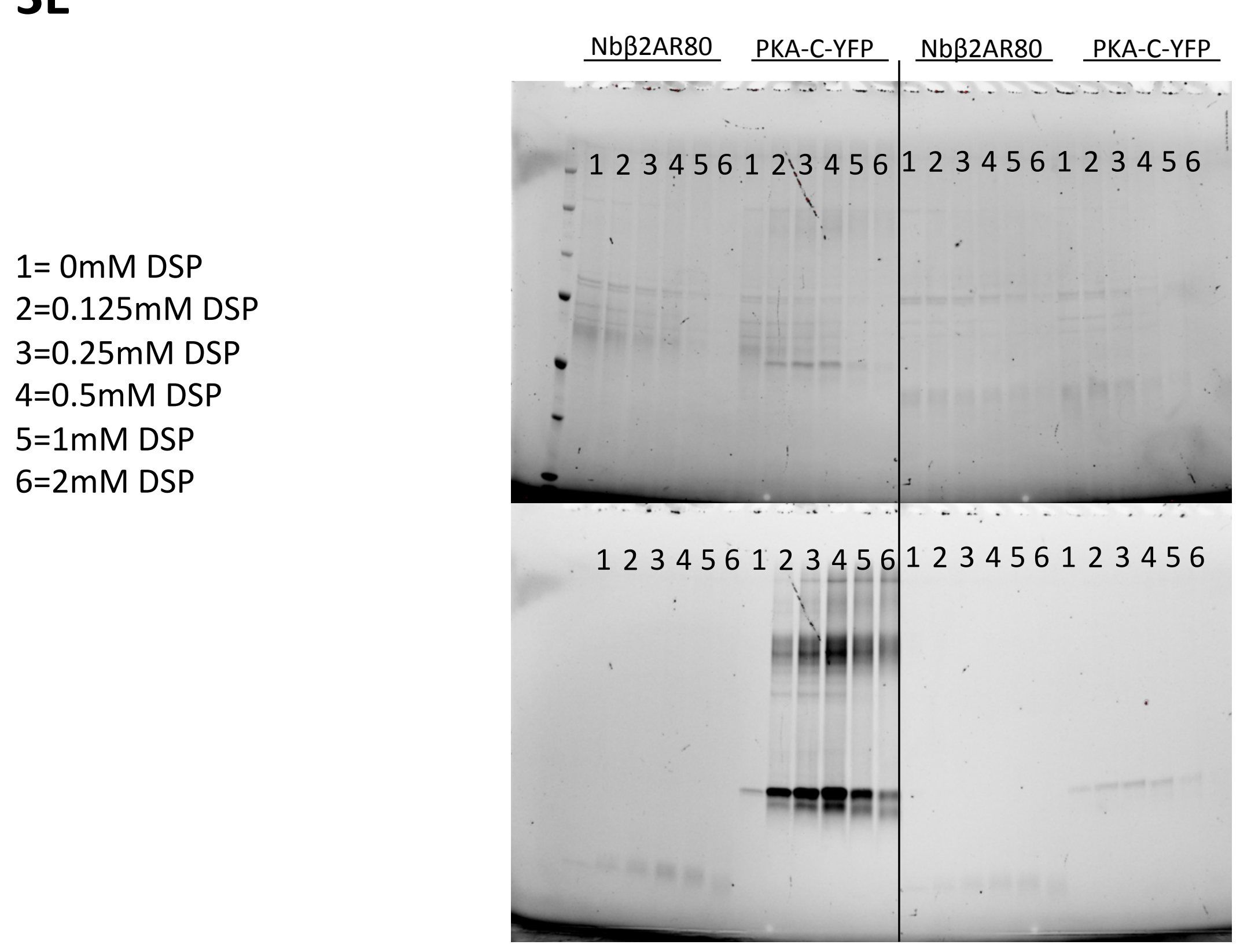

Total Protein (eluate)

Stain Free

YFP (eluate) 

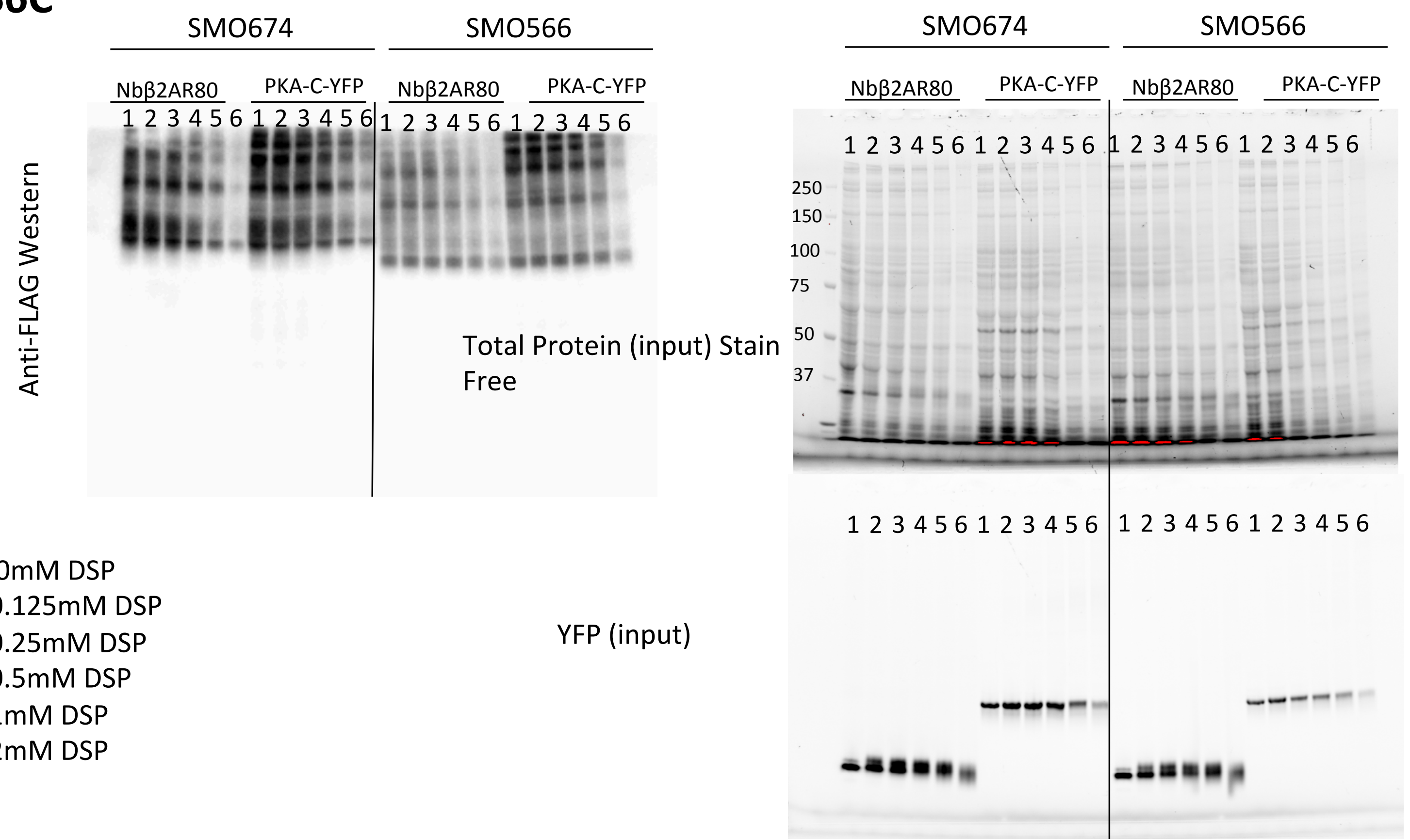

$1=0 \mathrm{mM} \mathrm{DSP}$

$2=0.125 \mathrm{mM}$ DSP

$3=0.25 \mathrm{mM}$ DSP

YFP (input)

$4=0.5 \mathrm{mM}$ DSP

$5=1 \mathrm{mM} \mathrm{DSP}$

$6=2 \mathrm{mM} \mathrm{DSP}$ 
Fig. S7B

Western Blot Anti-PKA-R

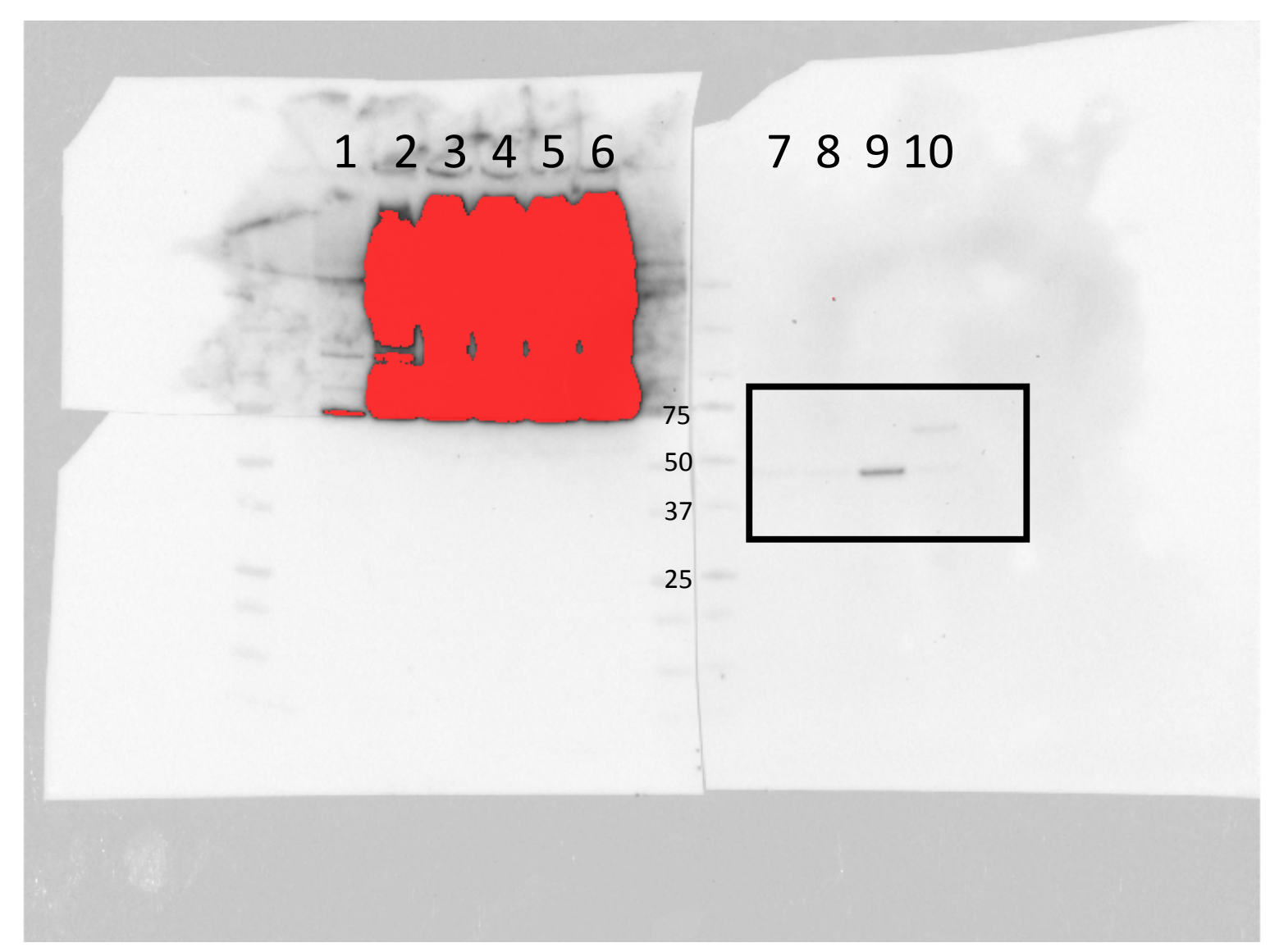


Fig. S8D

$\begin{array}{llllll}1 & 2 & 3 & 4 & 5 & 6\end{array}$

$\begin{array}{llllll}7 & 8 & 9 & 10 & 11 & 12\end{array}$

75

75

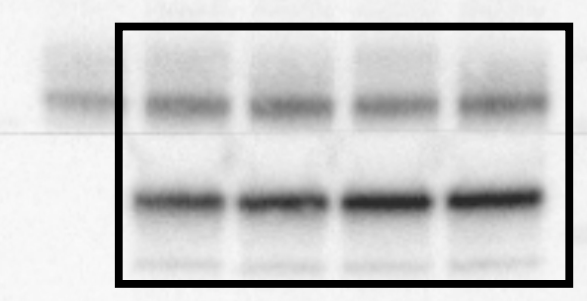

( -.. 
Fig. 6A

\section{Total Protein}

123456789111

012

123456789111

012

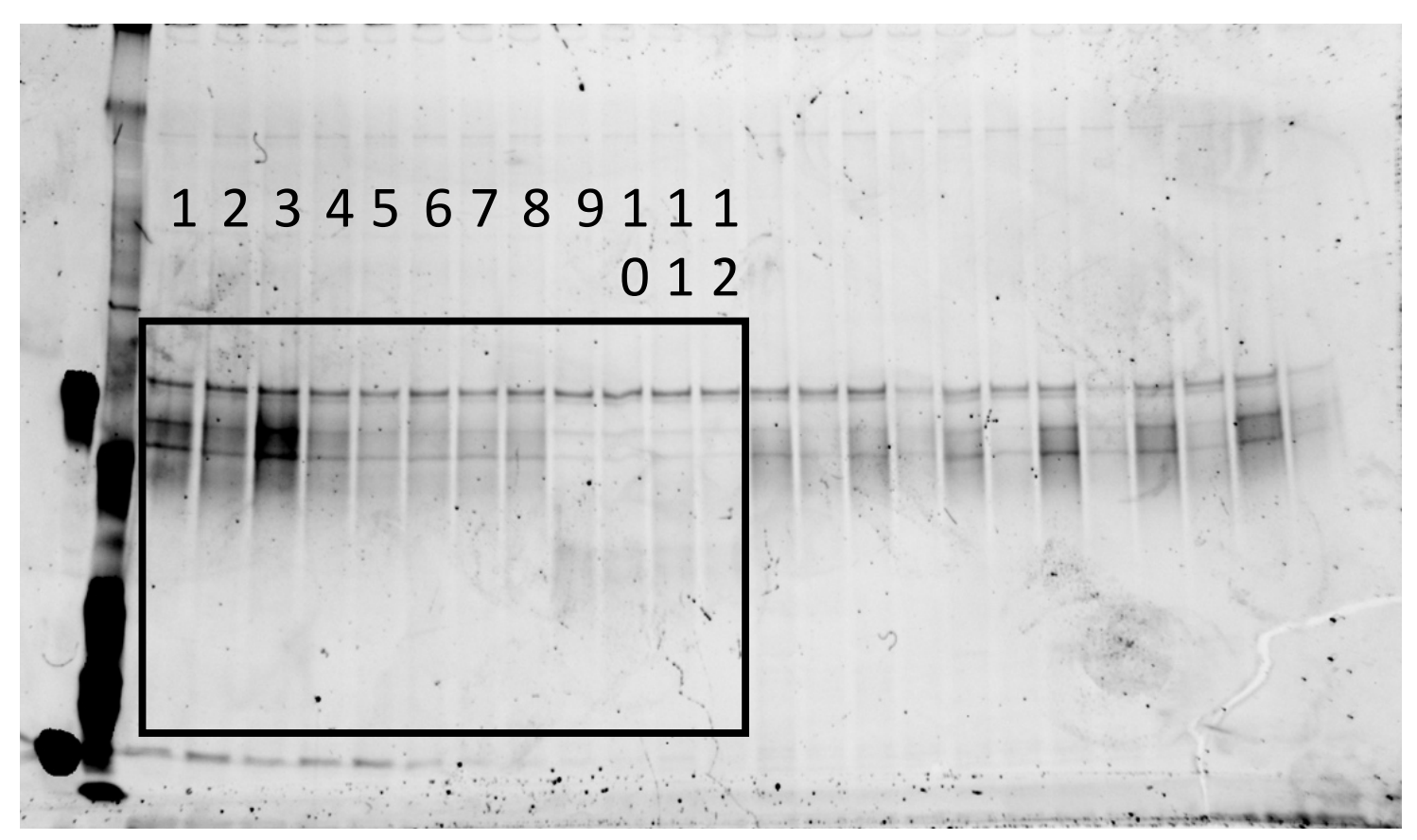

\section{ProQ Diamond}


Fig. 7C

$1=\mathrm{SMO} 074$

2=SMO566

$3=\mathrm{SMO}-\mathrm{NbSmo} 2$

$4=S M O-N b \beta 2 A R 80$

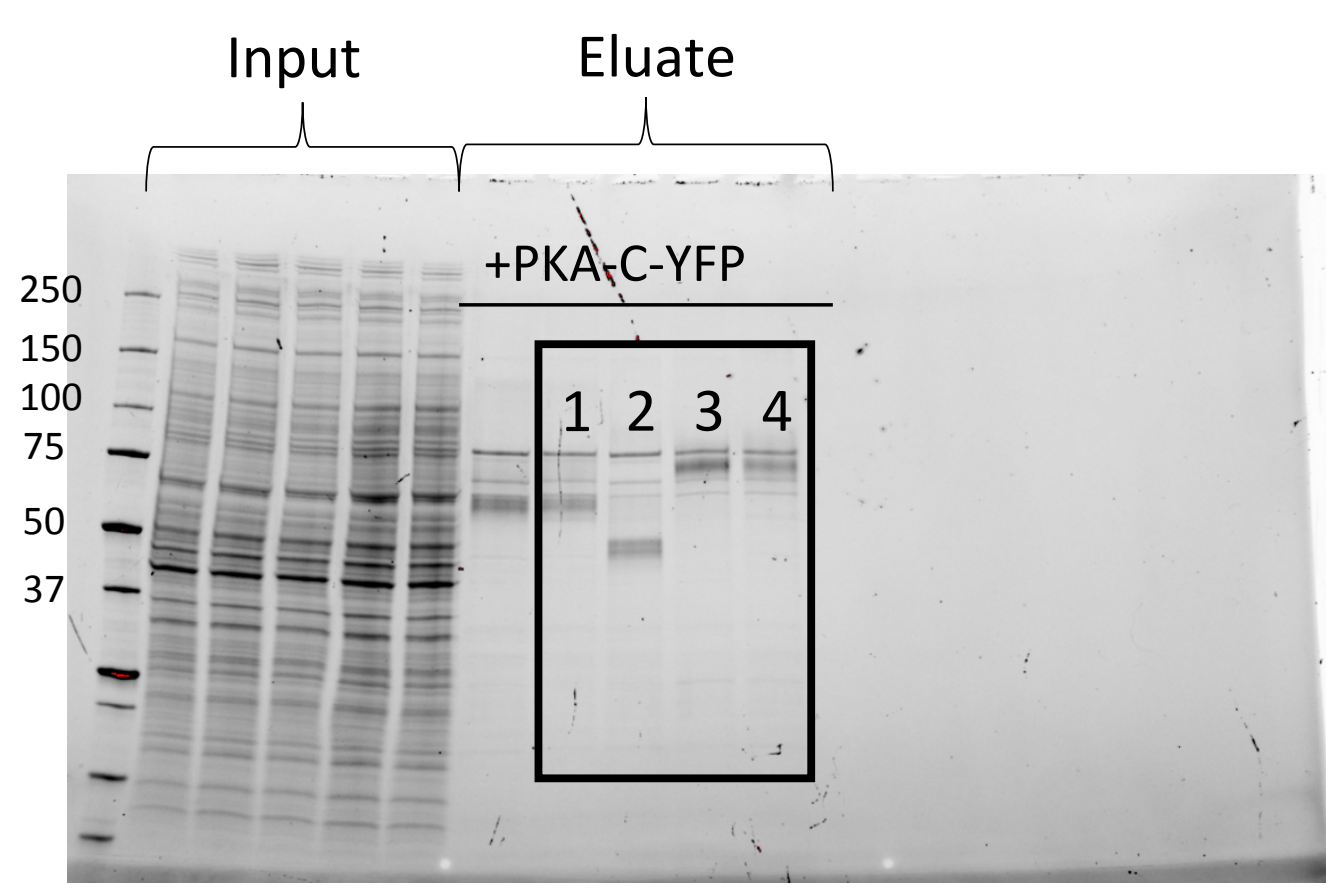

Total Protein

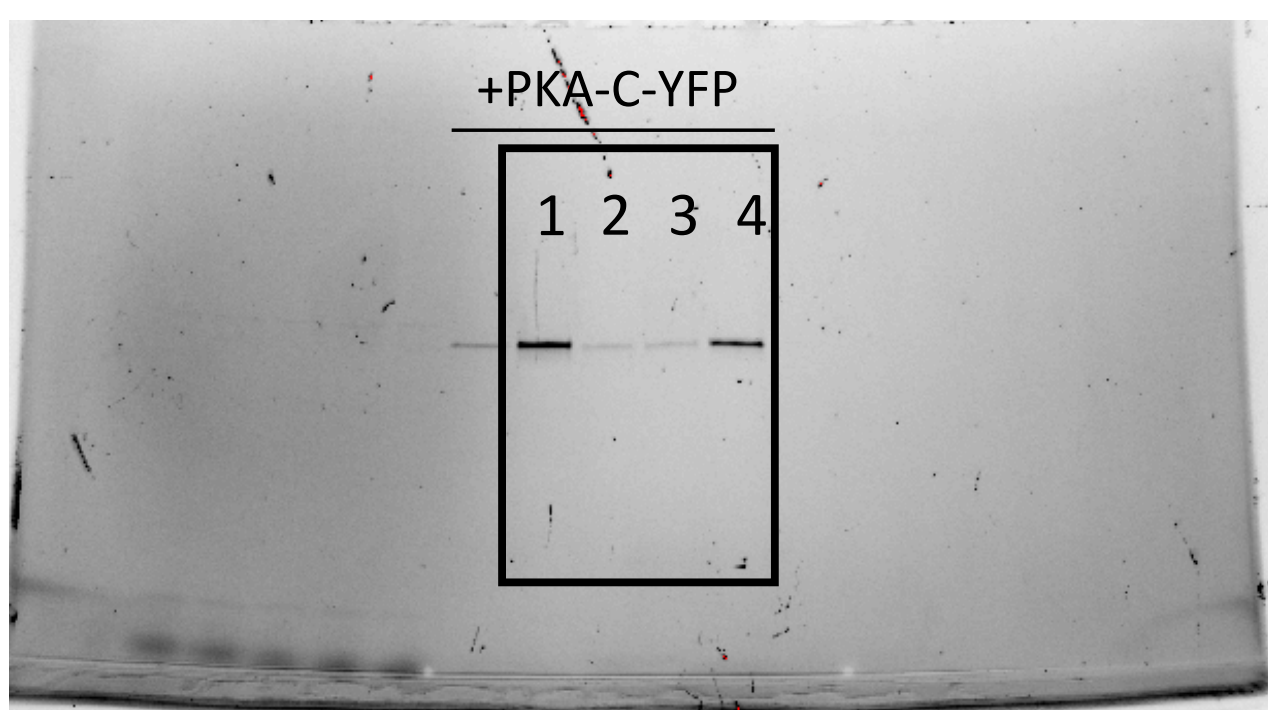

YFP 